\title{
CORRECTION
}

\section{Correction: Comparison of INVOS 5100C and Nonin SenSmart X-100 oximeter performance in preterm infants with spontaneous apnea}

Bjørn Andresen, Gorm Greisen and Simon Hyttel-Sorensen

Pediatric Research (2020) 87:1273; https://doi.org/10.1038/s41390-020-0869-7

Correction to: Pediatric Research https://doi.org/10.1038/s41390020-0752-6, published online 14 January 2020

This article was originally published with open access under a [CC BY 4.0] license. With the authors' decision to cancel Open
Access the copyright of the article has changed to ${ }^{\odot}$ [International Pediatric Research Foundation, Inc. 2020] with all rights reserved. 